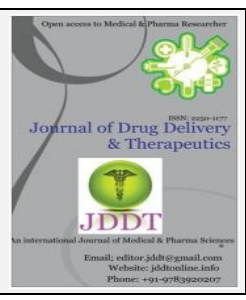

Open $\odot$ Access

Research Article

\title{
Extracellular Protease and DNase Activities in Clinical and Environmental Isolates of Cryptococcus neoformans Species Complex from Central India
}

\author{
Richa Gumasta1, 2*, Shesh Rao Nawange ${ }^{1,2}$, Shankar Mohan Singh 1,2, Abhijeet Garg ${ }^{3}$, Ruchi Sethi ${ }^{1,2}$, \\ Ruchika Yadu1, 2 \\ 1. Department of Biological Sciences, Rani Durgavati University, Jabalpur-482001 (M.P.) India \\ 2. Centre for Medical Mycology, Fungal Disease Diagnostic and Research Center, Society for Research, Diagnosis and Treatment of Human \\ Fungal Diseases, Jabalpur-482002 (M.P.) India. \\ 3. School of Biotechnology, Devi Ahilya Vishwavidyalaya, Indore, (M.P.) India.
}

\section{ABSTRACT}

Enzymes are important not only for the growth and multiplication of the microorganism but also in the infection, penetration of the host tissue and encountering host defense mechanisms. This study aims to investigate extracellular protease and DNase activity in clinical (20) and 120 environmental isolates of $C$. neoformans species complex collected from different localities of central India. DNase test agar containing toluidine blue and Yeast Carbon Base (YCB) agar medium supplemented with $0.1 \%$ BSA $+0.01 \%$ polypeptone was employed for the screening of DNase and protease production respectively. D Nase and protease production was detected by the appearance of clear zones around the colonies. On the basis of enzymatic activity and their Pz values, high protease production (Pz $\leq 0.6)$ was observed by 14 (11.6 \%) environmental and 4 (11.6 $\%$ ) clinical strains on $5^{\text {th }}$ day, whereas $35(29.16 \%)$ environmental and $8(40 \%)$ clinical strains were screened on $8^{\text {th }}$ day of incubation. Similarly $13(10.83 \%)$ environmental and $3(15 \%)$ clinical strains on the $5^{\text {th }}$ day, however 32 (26.66\%) environmental and 8 (40\%) clinical strains on the $8^{\text {th }}$ day of incubation were found to be high DNase producing strains with low Pz value (Pz $\left.\leq 0.6\right)$. In the case of protease activity, no significant difference was observed whereas a significant difference has shown by clinical $C$. neoformans and $C$. gattii strains on the $5^{\text {th }}$ day of DNase production $(\mathrm{p}<.001)$. Extracellular enzymes play a vital role in the pathogenicity and virulence of $C$. neoformans species complex, therefore, enzymes are considered as worthy targets for developing therapeutics.
\end{abstract}

Keywords: Cryptococcus neoformans species complex, Extracellular enzymes, DNase, protease, virulence, Pz value

Article Info: Received 09 July 2019; Review Completed 12 Aug 2019; Accepted 17 Aug 2019; Available online 30 Aug 2019

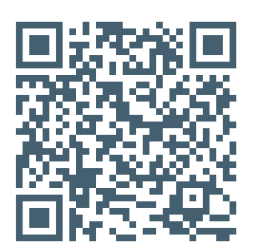

\section{Cite this article as:}

Gumasta R, Nawange SR, Singh SM, Garg A, Sethi R, Yadu R, Extracellular Protease and D Nase Activities in Clinical and Environmental Isolates of Cryptococcus neoformans Species Complex from Central India, Journal of Drug Delivery and Therapeutics. 2019; 9(4-A):328-333 http://dx.doi.org/10.22270/jddt.v9i4-A.3485

Richa Gumasta, Research Scholar, Dept. of Biological Sciences, R. D University, Jabalpur-482001 (M.P.) India

\section{INTRODUCTION:}

Opportunistic pathogens Cryptococcus neoformans and Cryptococcus gattii are the members of Cryptococcus neoformans species complex ${ }^{1}$. C. neoformans has been classified into two varieties and three serotypes i.e. serotype A for Cryptococcus. neoformans var. grubii, serotype D for $C$. neoformans var. neoformans and serotype AD for the hybrids of serotype A and D. C. gattii was previously known as $C$. neoformans var. gattii but currently it is considered as phylogenetically related but distinct species and contains serotype B and C2-5.

Cryptococcus neoformans and Cryptococcus gattii both species were reported for the production of a panoply of extracellular enzymes ${ }^{6}$ like proteases 7, urease ${ }^{8-9}$, phenoloxidase, phospholipases ${ }^{10}$ and DNase ${ }^{11}$.

C. neoformans infection commonly acquires from the environment ${ }^{12}$, the mechanism includes tissue invasion and is disseminated to other organs via the bloodstream from the lung 13-15. Studies of experimental infection in rats suggested $C$. neoformans produces tissue disrupting substances such as proteolytic enzymes through which it can penetrate the lung parenchyma and histopathological studies suggested in-vivo protease production which degrades collagen fibrils in infected tissues ${ }^{16}$.

Cryptococcal proteases have been associated with the virulence and are responsible for the destroying host tissues and for digesting several important host proteins such as collagen, elastin, fibrin, fibrinogen, immunoglobulins and complement factors $17,7,10$.

\section{MATERIAL AND METHODS:}

\section{Clinical and environmental isolates:}

In the present investigation, environmental and clinical samples were collected from various sources. Environmental sources include decaying woody debris inside the living tree 
trunk hollows, fruits, flowers of various plant species, soil, vegetables and desiccated excreta of a few species of caged birds, were collected from different localities of central India18. Clinical samples (blood, urine, CSF) of cancer patients were collected from Netaji Subhash Chandra Bose Medical College and Civil Hospital, Jabalpur City (Madhya Pradesh).

\section{Determination of protease production:}

Determination of protease production was performed in which all the isolates were evaluated for their ability to secrete protease on solid medium containing Bovine serum albumin (BSA) ${ }^{19}$.

Yeast carbon base (YCB) agar medium containing $11.7 \%$ YCB (Himedia Mumbai) supplemented with $0.1 \%$ BSA plus $0.01 \%$ polypeptone, $\mathrm{pH}$ was adjusted to 5 , sterilized by filtration through a membrane filter of $0.2 \mu \mathrm{m}$ pore size. To prepare $200 \mathrm{ml}$ of medium, $20 \mathrm{ml}$ of the YCB solution will be added to $160 \mathrm{ml}$ of $1.88 \%$ melted agar at $56^{\circ} \mathrm{C}$ and then $20 \mathrm{ml}$ of the BSA solution will be added to the medium. Twenty $\mathrm{ml}$ portions of the media thus prepared were poured into Petri dishes and media were referred to as YCB-BSA. Test isolates were grown on Sabouraud dextrose agar (SDA) for $24 \mathrm{hr}$ for $28^{\circ} \mathrm{C}$. Then each isolate was spot inoculated in triplicates and incubated at $37^{\circ} \mathrm{C}$ for 5 days. Then the plates were fixed with $10 \%$ trichloroacetic acid (TCA) for $2 \mathrm{hr}$ and then stained with Coomassie Brilliant Blue G-250. Protease production was detected by the appearance of proteolytic zones around the colonies. Reference strain C. albicans MTCC 227/ATCC 10231 served as positive control and strain of $C$. glabrata IHEM 22129 served as negative control.

\section{Determination of DNase production:}

The method used for detecting extracellular DNase production by C.neoformans sp. The complex was similar to the procedure used for detecting DNase production by Staphylococci. Plates of DNase Test Agar (Difco) supplemented with toluidine blue were prepared. Then each isolate was spot inoculated in triplicates and incubated at $30^{\circ} \mathrm{C}$ for 7 days. Then the inoculated plates were flooded with $1 \mathrm{~N}$ hydrochloric acid. Yeasts that depolymerized DNA contained in the medium exhibited clear zones surrounding the colonies, whereas those organisms which exhibited no extracellular DNase activity showed only the opaque background of precipitated DNA 20,11.

\section{Measurement and calculation of Pz value}

Protease and DNase activity was measured in terms of a ratio of the diameter of the colony to the total diameter of the colony plus zone of precipitation. Scoring was done according to the method described previously21. According to different $\mathrm{Pz}$ values strains were categorized into 5 different categories: -ve $(\mathrm{Pz}=1)$ very high $\mathrm{Pz}$ group (Negative for enzyme production), $+/-(\mathrm{Pz}=0.90-0.99)$ high $\mathrm{Pz}$ group, $++(\mathrm{Pz}=0.80-0.89)$ Intermediate, $+++(\mathrm{Pz}=0.70-$ $0.79)$ low $\mathrm{Pz}$ group, $++++(\mathrm{Pz} \leq 0.69)$ very low $\mathrm{Pz}$ group (large amount of enzyme production).The strains exhibiting $(-)$ and $(+)$ Pz groups were considered negative in the study.

\section{Statistical analysis:}

The data analysis was performed using SPSS statistics of independent ' $t$ ' test and the critical levels of significance of the results were considered at 0.05 levels i.e. $\mathrm{P}<0.001$ was considered significant for DNase activity.

\section{RESULT AND DISCUSSION:}

The present study was focused on the determination of DNase and protease activity on the clinical and environmental strains of Cryptococcus neoformans and Cryptococcus gattii. On the basis of enzymatic activity and their Pz values, clinical and environmental strains has been divided into five ranges, class and $\mathrm{Pz}$ groups. Results are shown in (Table $1 \& 2$ ).

Table 1. Scoring of Protease and DNase producing environmental isolates of Cryptococcus neoformans species complex into 5 different categories according to their different Pz values calculated on the $5^{\text {th }}$ and 8 th day of incubation.

\begin{tabular}{|c|c|c|c|c|c|c|c|}
\hline \multirow[t]{3}{*}{ Range } & \multirow[t]{3}{*}{ Class } & \multirow[t]{3}{*}{ Pz Group } & \multirow[t]{3}{*}{ Production } & \multicolumn{4}{|c|}{ Frequency of Environmental isolates } \\
\hline & & & & \multicolumn{2}{|c|}{$5^{\text {th }}$ day } & \multicolumn{2}{|c|}{$8^{\text {th }}$ day } \\
\hline & & & & Protease & DNase & Protease & DNase \\
\hline $\mathbf{P z}=1$ & - & Very high & No production & $21(17.5 \%)$ & $23(19.16 \%)$ & $10(8.33 \%)$ & $11(9.16 \%)$ \\
\hline$P z=0.9 .-0.99$ & $+/-$ & High & Very low & $28(23.3 \%)$ & $37(30.83 \%)$ & $11(9.16 \%)$ & $16(13.33 \%)$ \\
\hline$P z=0.8 .-0.89$ & ++ & Intermediate & Low & $27(22.5 \%)$ & $28(23.3 \%)$ & $26(21.66 \%)$ & $27(22.5 \%)$ \\
\hline$P z=0.70-0.79$ & +++ & Low & High & $30(25 \%)$ & $19(15.8 \%)$ & $38(31.66 \%)$ & $34(28.33 \%)$ \\
\hline $\mathrm{Pz}=\leq 0.69$ & ++++ & Very low & Very high & $14(11.6 \%)$ & $13(10.83 \%)$ & $35(29.16 \%)$ & $32(26.66 \%)$ \\
\hline
\end{tabular}

Table 2. Scoring of Protease and DNase producing clinical isolates of Cryptococcus neoformans species complex into 5 different categories according to their different $\mathrm{Pz}$ values calculated on the $5^{\text {th }}$ and 8 th day of incubation.

\begin{tabular}{|c|c|c|c|c|c|c|c|}
\hline \multirow[t]{3}{*}{ Range } & \multirow[t]{3}{*}{ Class } & \multirow[t]{3}{*}{ Pz Group } & \multirow[t]{3}{*}{ Production } & \multicolumn{4}{|c|}{ Frequency of Clinical Isolates } \\
\hline & & & & \multicolumn{2}{|c|}{$5^{\text {th }}$ day } & \multicolumn{2}{|c|}{$5^{\text {th }}$ day } \\
\hline & & & & Protease & DNase & Protease & DNase \\
\hline $\mathrm{Pz}=1$ & - & Very high & No production & $3(15 \%)$ & $3(15 \%)$ & $1(5 \%)$ & $2(10 \%)$ \\
\hline$P z=0.9 .-0.99$ & $+/-$ & High & Very low & $3(15 \%)$ & $5(25 \%)$ & $1(5 \%)$ & $2(10 \%)$ \\
\hline$P z=0.8 .-0.89$ & ++ & Intermediate & Low & $7(35 \%)$ & $3(15 \%)$ & $3(15 \%)$ & $5(25 \%)$ \\
\hline$P z=0.70-0.79$ & +++ & Low & High & $3(15 \%)$ & $6(30 \%)$ & $7(35 \%)$ & $3(15 \%)$ \\
\hline $\mathrm{Pz}=\leq 0.69$ & ++++ & Very low & Very high & $4(11.6 \%)$ & $3(15 \%)$ & $8(40 \%)$ & $8(40 \%)$ \\
\hline
\end{tabular}

Table 3 shows statistical results of enzymatic activity on 85 C. neoformans and 35 C. gattii isolates of environmental origin, $18 C$. neoformans and 35 C. gattii isolates from clinical samples of a cancer patient using SPSS software. 
Table 3. Test of Significance in Proteinase and DNase activities of environmental \& clinical $C$. neoformans and $C$. gattii isolates at 5 and 8 days of incubation using independent' $t$ ' test.

\begin{tabular}{|c|c|c|c|c|c|}
\hline Strain and types & $\begin{array}{l}\text { Number of } \\
\text { isolates }\end{array}$ & $\begin{array}{l}\text { Days of } \\
\text { incubation }\end{array}$ & $\begin{array}{l}\text { Enzymes } \\
\text { tested }\end{array}$ & $\begin{array}{l}\text { Positive } \\
\text { Production (\%age) }\end{array}$ & Significance \\
\hline \multirow{2}{*}{$\begin{array}{l}\text { Environmental } \\
\text { C. neoformans } \\
\text { C. gattii }\end{array}$} & \multirow{2}{*}{$\begin{array}{l}85 / 120 \\
35 / 120\end{array}$} & 5-days & \multirow{4}{*}{ Protease } & $99 / 120(82.5 \%)$ & NS \\
\hline & & 8-days & & $110 / 120(91.66 \%)$ & NS \\
\hline \multirow{2}{*}{$\begin{array}{l}\text { Clinical } \\
\text { C. neoformans } \\
\text { C. gattii }\end{array}$} & \multirow{2}{*}{$\begin{array}{l}18 / 20 \\
2 / 20\end{array}$} & 5-days & & $17 / 20(85 \%)$ & NS \\
\hline & & 8-days & & $19 / 20(95 \%)$ & NS \\
\hline \multirow{2}{*}{$\begin{array}{l}\text { Environmental } \\
\text { C. neoformans } \\
\text { C. gattii }\end{array}$} & \multirow{2}{*}{$\begin{array}{l}85 / 120 \\
35 / 120\end{array}$} & 5 -days & \multirow{4}{*}{ DNase } & $97 / 120(80.33 \%)$ & NS \\
\hline & & 8-days & & $109 / 120(90.83 \%)$ & NS \\
\hline \multirow{2}{*}{$\begin{array}{l}\text { Clinical } \\
\text { C. neoformans } \\
\text { C. gattii }\end{array}$} & \multirow{2}{*}{$\begin{array}{l}18 / 20 \\
2 / 20\end{array}$} & 5-days & & $20 / 20(100 \%)$ & $S(\mathbf{p}<\mathbf{0 . 0 0 1})$ \\
\hline & & 8-days & & $18 / 20(90 \%)$ & NS \\
\hline
\end{tabular}

NS (nonsignificant), S (significant, p<0.001)

Protease and DNase activity by the formation of clear zones around the Cryptococcus colonies were observed on the $5^{\text {th }}$ and $8^{\text {th }}$ day of incubation.

Figure 1 Protease activity seen by the formation of proteolytic zones around the Cryptococcus colonies with low Pz group (Pz=0.48).

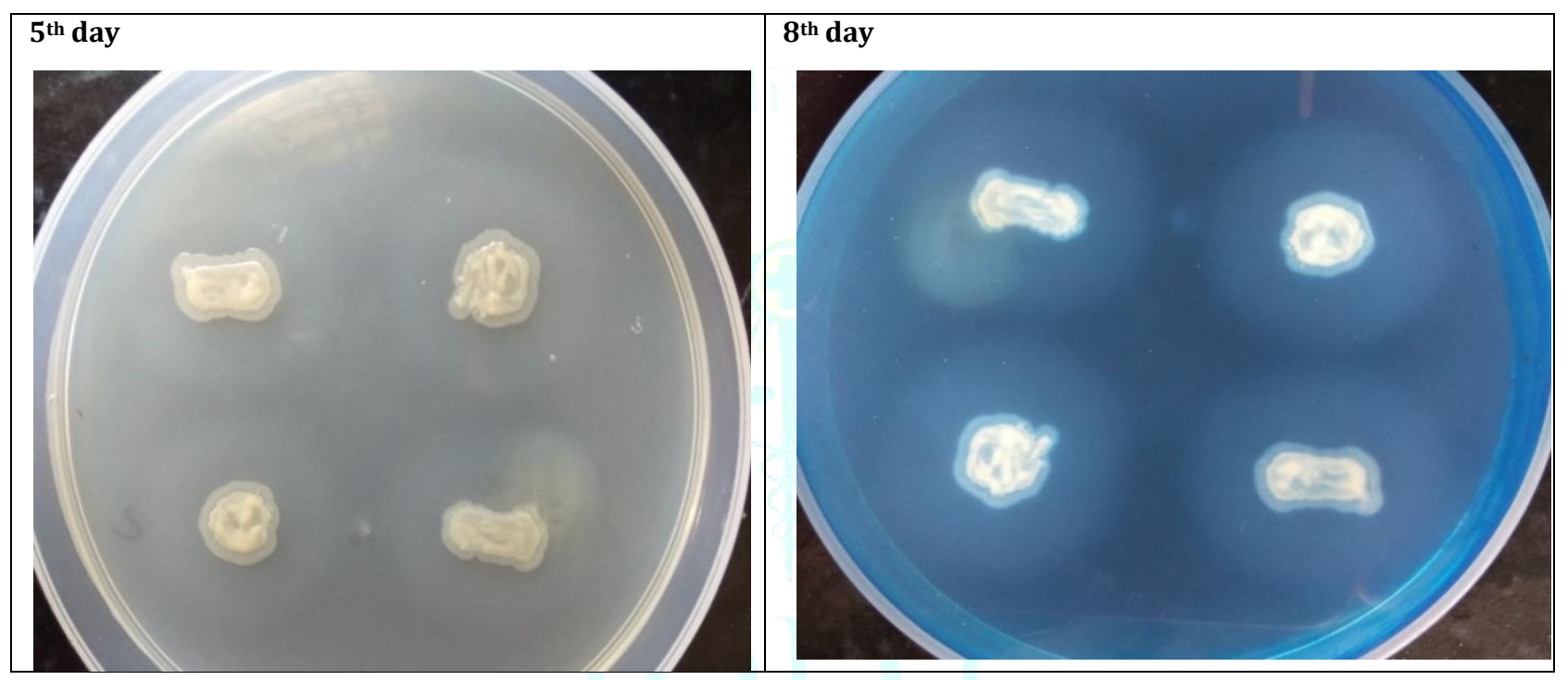

Figure 2. screening results for DNase production by the formation of clear zones around the Cryptococcus colonies on the 5th and $8^{\text {th }}$ day of incubation with low Pz group (Pz=0.51)

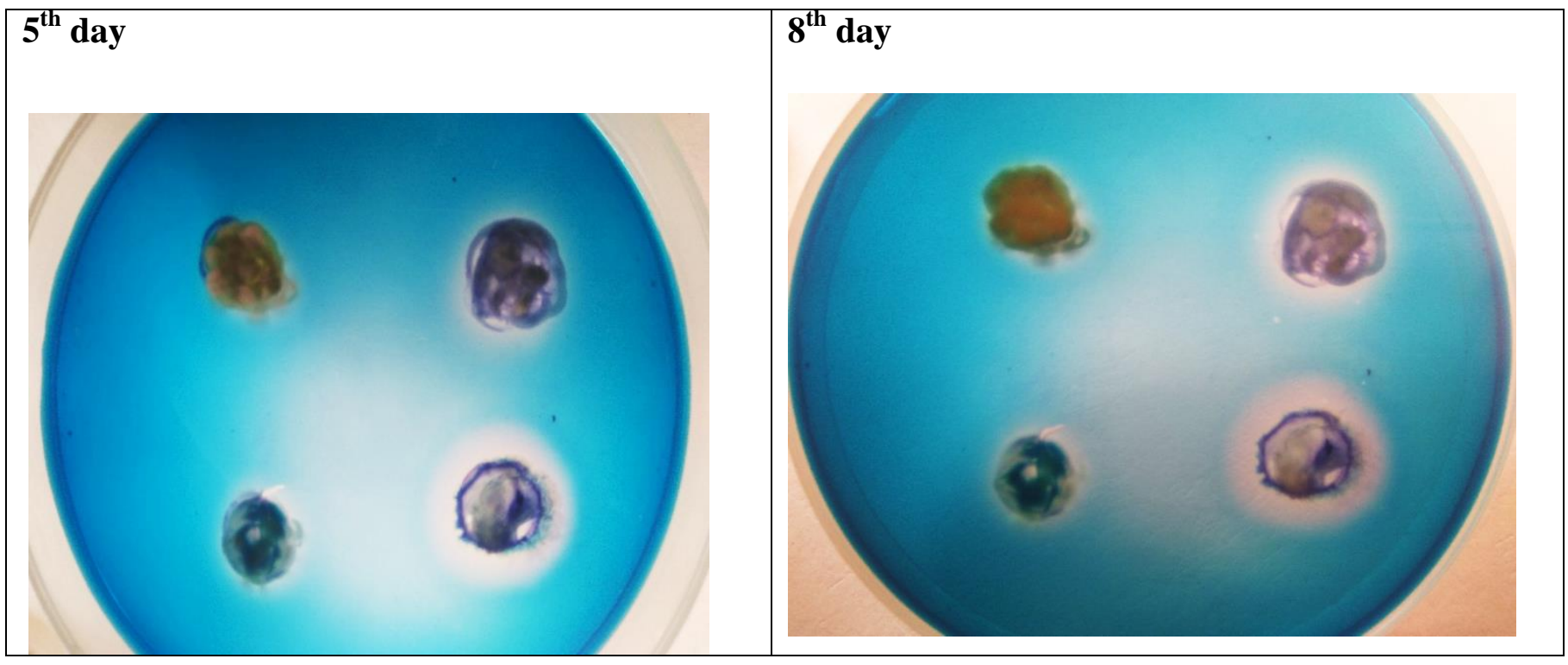


An evaluation of protease activity was done by determining the $\mathrm{Pz}$ values of all the environmental and clinical strains. High $\mathrm{Pz}$ values $(\mathrm{Pz}=1)$ were observed by $\mathrm{B} 1, \mathrm{~B} 3, \mathrm{C}-1, \mathrm{~T} 27$, T32, T 42, T45, T44, T46, T57, T61, T65, T69, T74, P9, P12, P19, P20, and P25. High protease production was exhibited by strains with isolate number: C-10 (C. neoformans var. grubii), isolated from a bone cancer patient. C-13 (C. neoformans var. grubii), isolated from a blood cancer patient, C-20 (C. neoformans var. grubii), isolated from ovarian cancer patient T-13 (C. gattii) isolated from living tree hollow of Terminalia. arjuna, T-38 (C. gattii), isolated from living tree hollow of Ficus religiosa and P-24 (C. neoformans. var. neoformans), isolated from pigeon excreta. Result was shown in Graph 3 and 4.
An evaluation of DNase activity was done by determining the $\mathrm{Pz}$ values of all the environmental and clinical strains. Highest $\mathrm{Pz}$ values $(\mathrm{Pz}=1)$ on $5^{\text {th }}$ day were observed by the C1, C6, C1, P6, P16, P18, P31, F1, T2, T13, T19, T23, B2, B3, T26, T41, T42, T47, B6, T63, T64, T68, T70. However high DNase production was obtained by strain C-8 (C. neoformans var. grubii), isolated from a lung cancer patient. C-14 (C. neoformans var. grubii), isolated from breast cancer patient, C-17 (C. neoformans var. grubii), isolated from breast cancer patient T32- (C. gattii) isolated from living tree hollow of Peltophorum dulce, T-35 (C. gattii), isolated from living tree hollow of Ficus religiosa, and P-24 (C. neoformans var. neoformans), isolated from pigeon excreta.
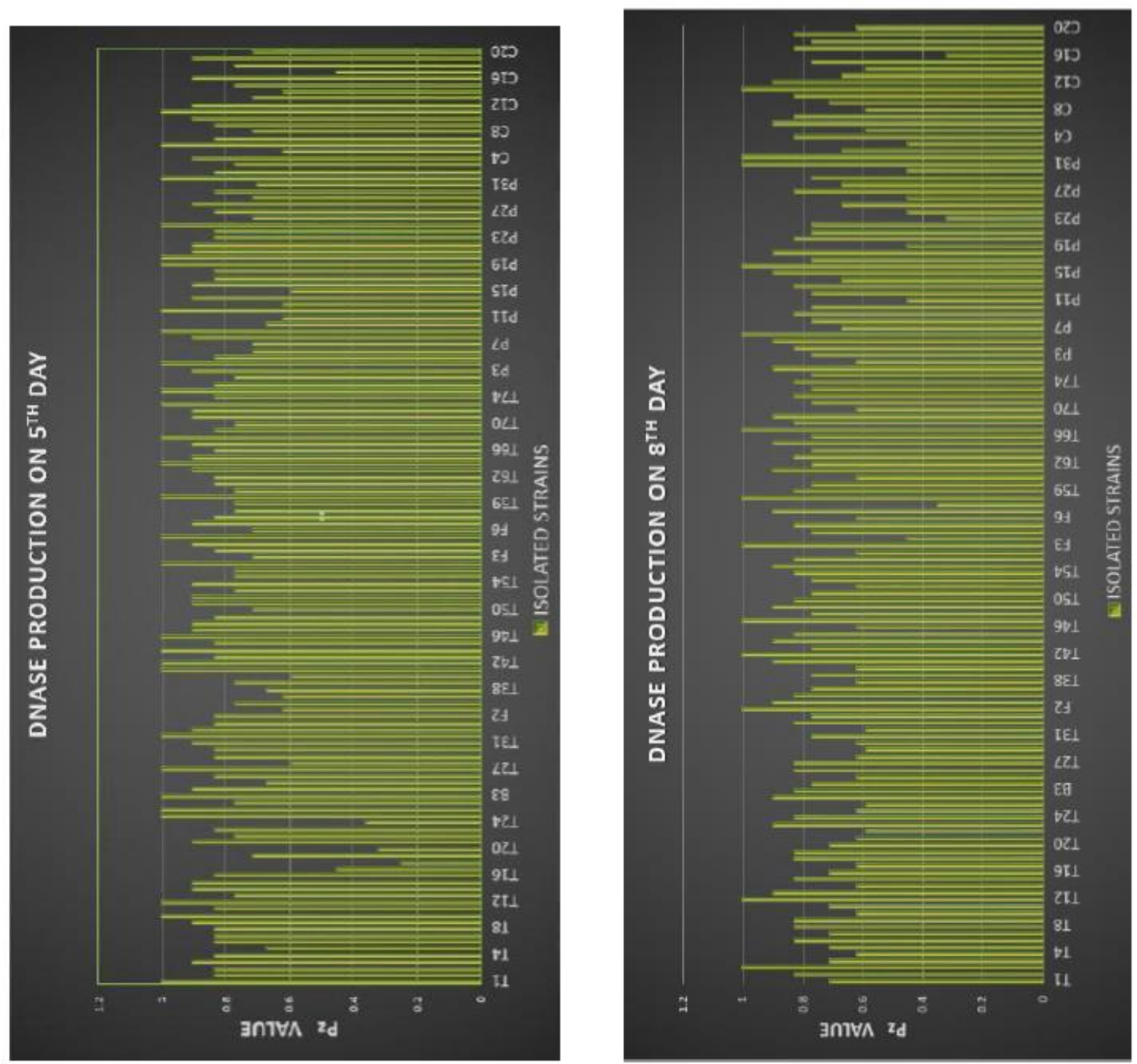

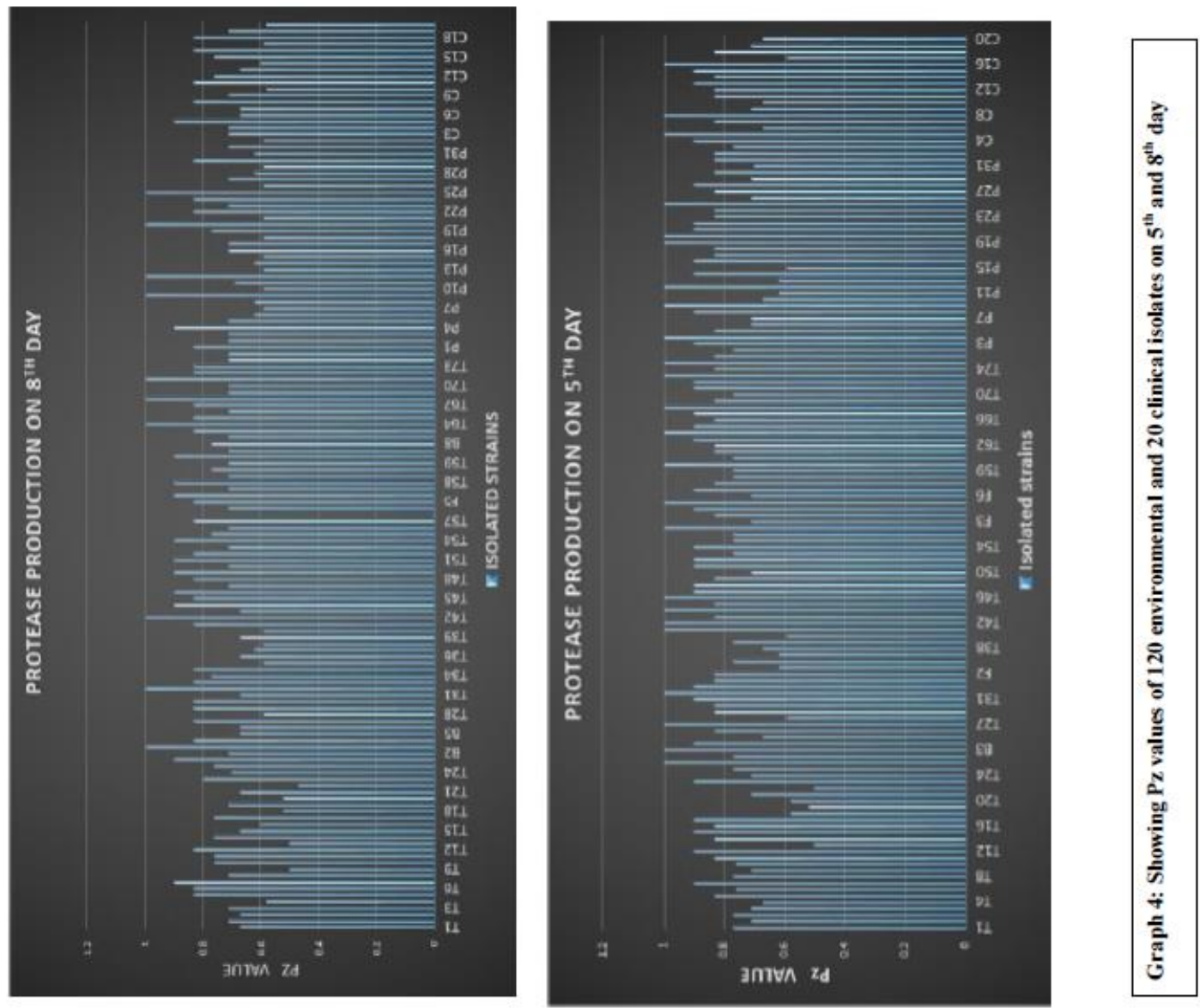

In this study we examined protease activity of $C$. neoformans and $C$. gattii of clinical and environmental origin by following the method 19 , in which extracellular protease activity was examined on 8 clinical (AIDS patients) strains of $C$ neoformans by solid and liquid YCB media supplemented with BSA and polypeptone, which is required as a carbon and nitrogen source, required for efficient and rapid growth in the early stages of development and important for the later efficient production of protease activity.

Identification and discrimination between clinical and environmental isolates of $C$. neoformans varieties can be done on the basis of extracellular enzyme activities 22 . However, we did not find any difference in the enzyme activities by clinical and environmental isolates of $C$. neoformans.

Our results support study who reported that both species produce extracellular DNase, but clinical isolates of $C$. neoformans produce significantly more extracellular DNase than environmental isolates 20. Extracellular DNase activity exhibits an essential role of in the taxonomic and phylogenetic studies of the genus Cryptococcus ${ }^{11}$.

In the present investigation, DNase activity was evaluated by clinical and environmental strains of Cryptococcus species. DNase activity is responsible for the elevation of the innate immune system in group A Streptococcus infection ${ }^{23}$. Similarly, in cryptococcal infection, neutrophils provoke an inflammatory response and found in close association with the infected tissue $24-25$.

In the present findings, a statistically no significant Difference was observed in the environmental and clinical isolates $C$. neoformans species complex positive for protease activity using independent ' $\mathrm{t}$ ' test $(\mathrm{p}<0.001)$. Whereas a significant difference was observed in the clinical strains on the $5^{\text {th }}$ day of DNase production.

\section{CONCLUSION:}

Analysis of the results obtained suggests that the capacity of Cryptococcus neoformans species Complex to produce protease and DNase may contribute to fungal virulence associated with cryptococcosis. This finding opens a new gateway for the research of new therapeutic strategies associated with these target virulence factors.

\section{ACKNOWLEDGMENT:}

The authors wish to thank the Vice-Chancellor of R. D University, Head of the Department of Biological Science of RD University for providing laboratory facilities and Prof S.M Singh for his valuable guidance. I owe a deep sense of gratitude to Dr. S.R Nawange, (SRDTHFD) for providing facilities required for my research work.

\section{REFERENCES:}

1. Lucas S, Martins M. da Luz, Flores O, Meyer W, SpencerMartins I, Inacio J. Differentiation of Cryptococcus neoformans varieties and Cryptococcus gatti using CAP59-based loopmediated isothermal DNA amplification. Clin Microbiol Infect 2010;16:711-714

2. Kwon-Chung KJ and Bennett JE. Cryptococcus and Cryptococcosis. In: Kwon-Chung KJ, Bennett JE, editors. Medical Mycology, Philadelphia, London: Lea and Febiger. 1992; 397-446.

3. Franzot SP, Salkin IR, Casadevall A. Cryptococcus neoformans var. grubii: separate varietal status for Cryptococcus neoformans serotype A isolates. J Clin Microbiol. 1999; 37: 838-840.

4. Boekhout T, Theelen B, Diaz M et al. Hybrid genotypes in the pathogenic yeast Cryptococcus neoformans. Microbiology. 2001; 147: 891-907. 
5. Kwon-Chung KJ and Varma A. Do major species concepts support one, two or more species within Cryptococcus neoformans? FEMS Yeast Res. 2006; 6: 574-587

6. Perfect JR. Cryptococcus neoformans: a sugar-coated killer. In: Heitman J et al., editors. Molecular principles of fungal pathogenesis. Washington: ASM Press; 2006; 281-303.

7. Brueske $\mathrm{CH}$. Proteolytic activity of a clinical isolate of Cryptococcus neoformans. J Clin Microbiol. 1986;23:631-3

8. Kwon-Chung KJ, Wickes BL, Booth JL et al. Urease inhibition by EDTA in the two varieties of Cryptococcus neoformans. Infect Immun. 1987; 55:1751-4.

9. Torres-Rodriguez JM, Alvarado-Ramirez E, Gutierrez-Gallego R. Urease activity in Cryptococcus neoformans and Cryptococcus gattii. Rev Iberoam Micol. 2008; 25:27-31

10. Chen SC, Muller M, Zhou JZ et al. Phospholipase activity in Cryptococcus neoformans: a new virulence factor? J Infect Dis. 1997; 175:414-20.

11. Cazin Jr J, Kozel TR, Lupan DM, et al. Extracellular deoxyribonuclease production by yeasts. J Bacteriol. 1969;100:760-2.

12. Lin X, Heitman J. The biology of the Cryptococcus neoformans species complex. Annu Rev Microbiol. 2006; 60: 69-105

13. Ellis DH and Pfeiffer TJ. Natural habitat of Cryptococcus neoformans var. gattii. J Clin Microbiol. 1990; 28: 1642-1644

14. Chen LC, Blank ES, Casadevall A. Extracellular protease activity of Cryptococcus neoformans. Clin Diagn Lab Immunol. 1996; 3:570-4.

15. Sukroongreung S, Kitiniyom K, Nilakul C et al. Pathogenicity of basidiospores of Filobasidiella neoformans var. neoformans. Med Mycol. 1998; 36: 419-424.
16. Salkowski C.A and Balish E. Cutaneous cryptococcosis in athymic and beige-athymic mice. Infect. Immun. 1991; 59: 1785-1789.

17. Muller HE, Sathi KK. Proteolytic activity of Cryptococcus neoformans against human plasma proteins.Med Microbiol Immunol 1972; 158: 129-34.

18. Grover N, Nawange SR, Naidu J et al. Ecological niche of Cryptococcus neoformans var. grubii and Cryptococcus gattii in decaying wood of trunk hollows of living trees in Jabalpur City of Central India. Mycopathol. 2007; 164: 159-170.

19. Aoki S, Ito-kuwa S, Nakamura Y, et al. Extracellular proteolytic activity of Cryptococcus neoformans.. Mycopathol. 1994; 128:143-150.

20. Sanchez, M and Colom F. Extracellular DNase activity of Cryptococcus neoformans and Cryptococcus gattii, Rev Iberoam Micol, 2010; (1), pp 10 - 13.

21. Price MF, Wilkinson ID, Gentry LO. Plate Method for detection of Phospholipase activity in Candida albicans. Sabouraudia 1982; 20:7-14.

22. Vidotto V, Ito-Kuwa S, Nakamura $\mathrm{K}$ et al. Extracellular enzymatic activities in Cryptococcus neoformans strains isolated from AIDS patients in different countries. Rev Iberoam Micol. 2006; 23:216-20.

23. Sumby P, Barbian KD, Gardner DJ et al. Extracellular deoxyribonuclease made by group A Streptococcus assists pathogenesis by enhancing evasion of the innate immune response. Proc Natl Acad Sci USA. 2005; 102:1679-84.

24. Fazekas G and Schwarz J. Histology of experimental murine cryptococcosis. Am J Pathol. 1958; 34:517-29.

25. Levine S, Zimmerman HM, Scorza A. Experimental cryptococcosis (torulosis). Am J Pathol. 1957; 33:385-409. 